\title{
METODE TOPSIS SISTEM PENDUKUNG KEPUTUSAN DALAM MEMILIH MURID PAUD TELADAN
}

\author{
Tri Rahayu $^{1 *}$, Erly Krisnanik ${ }^{2}$, Anita Muliawati ${ }^{3}$ \\ 123Program Studi Pendidikan Sistem Informasi, Universitas Pembangunan Nasional Veteran Jakarta, Indonesia \\ Jl. RS. Fatmawati Pondok Labu Jakarta \\ *Corresponding Author: trirahayu@unpvj.ac.id
}

\begin{abstract}
ABSTRAK
Dalam menentukan keputusan diperlukan suatu metode yang tepat dan cepat. Salah satu diantaranya metode yang akan digunakan pada penelitian ini yaitu Metode TOPSIS. dalam hal ini menentukan penilaian murid paud teladan akan diproses dengan metode tersebut. Tahapan pertama yang dilakukan yaitu menentukan kriteriakriteria yaitu; kreatif, sopan santun, keluwesan berbicara, disiplin dan jujur. kemudian tiap-tiap kriteria diberi bobot yang diproses dengan metode TOPSIS. Tingkat kepentingan kriteria ditentukan oleh tim penilai atau guru yang disini dianggap sebagai pakar. Setelah bobot penilaian kriteria kemudian dilakukan uji validasi atau uji kompetensi yang menentukan terpenuhi atau tidak kriteria tersebut. Jika layak maka data murid dapat dilakukan untuk menentukan murid paud teladan. Murid paud teladan bukan murid yang pintar berdasarkan akademik tapi lebih kepada karakteristik. Dimana pendidikan karakteristik sejak dini sangatlah penting untuk menentukan perkembangan jiwa anak menjadi manusia yang berakhlak baik. Dari hasil penelitian tersebut sebagai rekomendasi untuk menentukan penilaian murid paud teladan dapat menggunakan metode TOPSIS. Hasil dari perhitungan dengan metode topsis menentukan murid Paud Teladan kriteria didapat hasilnya yaitu: M. Reyhan (4.009159391), M. Hilmansyah (1.22061695), Cindy Clarisa (1.139252405), Mikail (0.56050508) dan Alika (0.516405616). Sehingga preferensi tertinggi dalam menentukan murid paud teladan adalah M. Reyhan dan terendah adalah Alika.
\end{abstract}

Kata Kunci: TOPSIS, Metode, Murid Paud Teladan

\begin{abstract}
In determining the decision needed an appropriate and fast method. One of them is the method that will be used in this research, the TOPSIS Method. in this case determine the assessment of student kindergarten model will be processed by the method. The first stage is to determine the criteria namely; creative, good manners, flexibility of speech, discipline and honesty. then each criterion is given a weight which is processed by the TOPSIS method. The importance of the criteria is determined by the assessment team or the teacher who is considered an expert here. After the weighting of the criteria evaluation is then conducted a validation test or competency test that determines whether or not the criteria are met. If it is feasible, student data can be made to determine the students' role models. The of student kindergarten are not students who are smart based on academics but rather are characteristic. Where the characteristics of education from an early age is very important to determine the development of a child's soul into a man of good character. From the results of the study as a recommendation to determine the assessment of student kindergarten can use the TOPSIS method. The results of calculations with the topsis method determine the criteria of the student kindergarten, the results are: M. Reyhan (4.009), M. Hilmansyah (1.220), Cindy Clarisa (1.139), Michael (0.560) and Alika (0.516). So that the highest preference in determining pupils or role models is M. Reyhan and the lowest is Alika.
\end{abstract}

Keywords: TOPSIS, Methods, student kindergarten

\section{PENDAHULUAN}

Konsep Sistem Pendukung Keputusan (SPK) pertama kali diungkapkan pada tahun 1971 oleh
Michael Scoot Morton [1] dengan istilah Multiple Criteria Decision Making (MCDM) pengambilan keputusan untuk menetapkan alternatif terbaik dari sejumlah alternatif berdasarkan beberapa kriteria 
tertentu. Kriteria biasanya berupa ukuran-ukuran, aturan-aturan, atau standar yang digunakan dalam pengambilan keputusan. Didalam MCDM terdapat metode TOPSIS (Technique for Order Preference by Similarity to Ideal Solution). TOPSIS adalah metode yang didasarkan pada konsep dimana alternatif terpilih yang terbaik tidak hanya memiliki jarak terpendek dari solusi ideal positif, namun juga memiliki jarak terpanjang dari solusi ideal negatif.

SPK sangat diperlu di era sekarang ini yang lebih terkenal dengan jaman milenia, kemudian sejumlah perusahaan, lembaga penelitian dan perguruan tinggi mulai melakukan penelitian dan membangun Sistem Pendukung Keputusan, sehingga dari produksi yang dihasilkan dapat disimpulkan bahwa sistem ini merupakan suatu sistem berbasis komputer yang ditujukan untuk membantu pengambilan keputusan dalam memanfaatkan data dan model tertentu untuk memecahkan berbagai persoalan yang tidak terstruktur[2]. Sampai ketingkat pendidikan paud pun SPK juga dibutuh untuk menentukan murid paud teladan. Konsep murid teladan berbeda dengan murid berprestasi. Murid berprestasi cenderung berorientasi pada hasil belajar siswa bidang akademis. Penentuan murid berprestasi umumnya berdasarkan hasil belajar yang diperoleh pada akhir semester. Berbeda dengan murid teladan. murid teladan mengacu pada sikap dan tingkah laku murid di sekolah. Oleh sebab itu murid teladan ditentukan melalui pemilihan dengan prosedur tertentu. Yang memilih adalah semua anggota komunitas sekolah. Guru-guru dan pegawai administrasi dan murid murid yang ada di sekolah tersebut. murid yang terpilih menjadi murid teladan boleh jadi bukan murid yang berprestasi dibidang akademis. Atau bisa juga akan terpilih sebagai murid teladan dari murid berprestasi. Tergantung pilihan anggota komunitas murid di sekolah itu. Sudah barang tentu, menjadi murid teladan tidak akan mudah karena dipengaruhi sejauh mana ketertarikan pemilih terhadap sikap dan tingkah laku murid sehari-hari di sekolah. Jelas hal ini bersifat subjektif namun kategorinya tetap sikap dan tingkah laku murid yang pantas menjadi acuan dan teladan bagi murid lain. Barangkali, hal ini bermanfaat untuk mengurangi kenakalan murid di sekolah.

Penelitian ini melakukan analisa metode TOPSIS dalam menentukan murid teladan. Kriteria - kriteria yang digunakan adalah kreatif, sopan santun, keluwesan berbicara, disiplin dan jujur. Dengan demikian karakter murid - murid dapat dilihat lebih awal dan Pendidikan karakter untuk anak usia dini itu sangat penting, karena upaya penanaman nilainilai karakter kepada murid paud sejak dini yang meliputi pengetahuan, kesadaran atau kemauan, dan tindakan untuk melaksanakan nilai-nilai kebaikan dan kebajikan, kepada Tuhan YME, diri sendiri, sesama, lingkungan maupun kebangsaan agar menjadi manusia yang berakhlak [4].

Hasil dari perhitungan dengan metode topsis menentukan murid Paud Telada kriteria didapat hasilnya yaitu: M. Reyhan (4.009159391), M. Hilmansyah (1.22061695), Cindy Clarisa (1.139252405), Mikail (0.56050508) dan Alika (0.516405616). Sehingga preferensi tertinggi dalam menentukan murid pau teladan adalah M. Reyhan dan terendah adalah Alika.

\section{METODE}

Metodologi penelitian yang akan dilakukan dalam penelitian ini dimulai dari gambaran umum alur penelitian, perancangan penelitian sampai teknik yang digunakan dalam melakukan pengolahan data. Metode yang digunakan untuk melakukan pengolahan data yaitu menggunakan TOPSIS.

Pendekatan yang digunakan dalam penelitian ini adalah menganalisa metode TOPSIS berdasarkan kriteria-kriteria yang telah ditentukan didalam menentukan murid paud teladan. Dengan menentukan kriteria-kriteria dan diberikan bobot penelitiannya berdasar kan tim penilai, pakar atau guru didalam menentukan penilaiannya. Tahapan penelitian dapat dilihat pada gambar 1 .

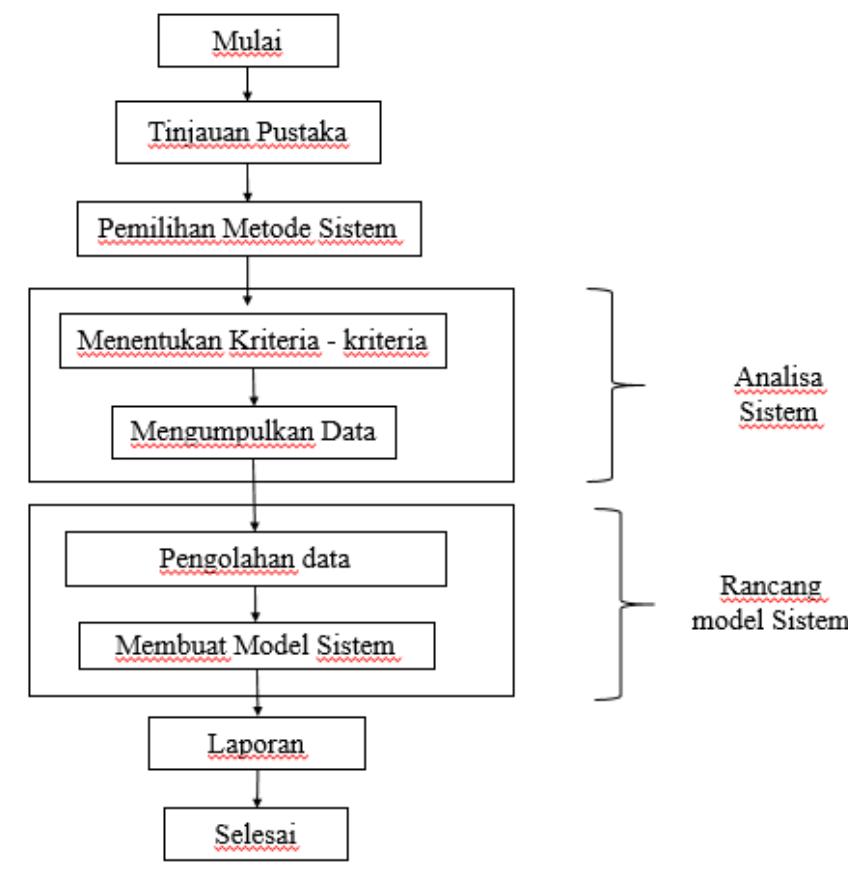

Gambar 1. Tahapan Penelitian

Tahapan penelitian yang dilakukan pada penelitian ini dapat dilihat pada gambar 1 diuraikan sebagai berikut: 


\section{Tinjauan Pustaka}

Melakukan tinjauan dan studi literatur terhadap target riset pada TK Paud Assibyan di desa curug kecamatan baros kabupaten serang propinsi Banten.

\section{Pemilihan Metode}

Menentukan metode yang digunakan dalam penelitian ini yang nantinya digunakn sebagai tools dalam pengolahan data. Pada penelitian ini menggunakan metode TOPSIS sebagai alat ukur untuk menetukan skala teladan pada murid paud.

\section{Analisa Sistem}

Hasil analisa dari literatur, wawancara dan observasi maka diperoleh kriteria - kriteria untuk menentukan murid paud teladan yaitu; kreatif, sopan santun, keluwesan berbicara, disiplin dan jujur. Kemudian dilakukan pembobotan dari kriteria-kriteria dengan menggunakan metode TOPSIS.

\section{Rancangan Sistem}

Data murid paud yang diperoleh diolah berdasarkan metode topsis, dimana dalam hal ini menentukan terlebi dahulu skala penilaian berdasarkan kriteria-kriteria yang ditetapkan. Dengan demikian metode tersebut dalam diterapkan berdasarkan data-data murid paud yang telah diperoleh.

\section{Laporan}

Dari hasil penelitian dilakukan tahap laporan akhir kegiatan penelitian dan nanti akan dilanjutkan dengan pembuatan jurnal penelitian sebagai kegiatan akhir penelitian.

\section{Kesimpulan}

Hasil dari penelitian ini dapat digunakan untuk membuat aplikasi dalam mengambil keputusan dalam menentukan murud paud teladan. Penelitian ini bertujuan untuk melakukan penilain atau skala pengukuran system untuk menentukan murid paud teladan dengan menggunakan metode TOPSIS agar dapat dihasilkan suatu alternative keputusan guna membantu dalam mengambil suatu keputusan. Hasil penelitian ini diharapkan dapat memberikan kontribusi murid paud yang selama ini penilaian selalu menilain murid paud berdasarkan nilai tertinggi dalam bidang akademik, sedangkan untuk penilain keteladanan lebih penilaian karakter diri murid paud tersebut. Metode TOPSIS digunakan diharapkan adanya unsur obyektifitas didalam pengambilan keputusan dan meminimalkan human error. Dengan demikian proses pengolahan data dan pengambil keputusan menjadi lebih cepat dalam menentukan murid paud teladan. Menentukan skala kriteria berdasarkan dari tim penilai yaitu guru.

\section{Langkah-langkah Metode Topsis}

TOPSIS adalah metode yang dikenalkan pertama kali oleh Yoon dan Hwang, dimana alternatif yang dipilih memiliki jarak terdekat dengan solusi ideal positif dan memiliki jarak terjauh dari solusi ideal negatif.

Langkah-langkah yang dilakukan dalam menyelesaikan suatu permasalahan menggunakan metode TOPSIS adalah sebagai berikut:

1. Menggambarkan alternatif (m) dan kriteria (n) ke dalam sebuah matriks, dimana $\mathrm{Xij}$ dalah pengukuran pilihan dari alternatif ke-i dan kriteria ke-j. Matriks ini dapat dilihat pada persamaan (1).

$$
\mathbf{D}=\left|\begin{array}{ccc}
X_{11} & X_{12} \ldots & X_{13} \\
X_{21} & X_{22 \ldots} & X_{23} \\
X_{31} & X_{32 \ldots} & X_{33}
\end{array}\right|
$$

2. Membuat matriks $\mathrm{R}$ yaitu matriks keputusan ternormalisasi setiap normalisasidari nilai rij dapat dilakukan dengan perhitungan menggunakan persamaan (2).

$$
r_{i j}=\frac{x_{i j}}{\sqrt{\sum_{n=1}^{m} x_{i j}}}
$$

3. Membuat pembobotan pada matriks yang telah dinormalisasi Setelah dinormalisasi Y, setiap kolom pada matriks $\mathrm{R}$ dikalikan dengan bobot (wj) untuk menghasilkan matriks pada persamaan (3).

$$
\mathbf{Y}=\left|\begin{array}{ccc}
W_{1} r_{11} & W_{1} r_{12} & W_{n} r_{n} \\
W_{2} r_{21} & \ldots \ldots & \ldots \ldots \\
W_{J} r_{M 1} & W_{J} r_{m 2} & W_{J} r_{m m}
\end{array}\right|
$$

4. Menentukan nilai solusi ideal positif dan solusi ideal negatif. Solusi ideal dinotasikan $A+$, dapat dilihat pada persamaan (4)

$$
\begin{gathered}
A^{+}=\left\{\left(\max Y_{i j} \mid \mathrm{j} € \mathrm{~J}\right),\left(\min Y_{i j} \mid \mathrm{j} € \mathrm{j}^{\prime}\right), \mathrm{i}=1,2,3 \ldots, \mathrm{m}\right\}(4) \\
A^{+}=\left(Y_{1}^{+}, Y_{2}^{+}, Y_{3}^{+}, \ldots, Y_{n}^{+}\right)
\end{gathered}
$$

sedangkan solusi ideal negatif dinotasikan A-. Persamaan untuk menentukan solusi ideal dapat dilihat pada persamaan (5).

$$
\begin{gathered}
A^{-}=\left\{\left(\min Y_{i j} \mid \mathrm{j} € \mathrm{~J}\right),\left(\max Y_{i j} \mid \mathrm{j} € \mathrm{j}^{\prime}\right), \mathrm{i}=1,2,3 . ., \mathrm{m}\right\} \\
A^{+}=\left(Y_{1}^{+}, Y_{2}^{+}, Y_{3}^{+}, \ldots, Y_{n}^{+}\right)
\end{gathered}
$$


Keterangan

$\mathrm{j}=$ Himpunan kriteria keuntungan (benefit criteria)

$\mathrm{j}^{\prime} \quad=$ Himpunan kriteria biaya (cost criteria)

Yij = elemen dari matriks keputusan yang ternormalisasi

$\mathrm{Y}^{+}{ }_{\mathrm{j}}=\max \{\mathrm{Yij}\} ;$ jika $\mathrm{j}$ adalah atribut keuntungan (benefit criteria)

$\mathrm{Y}^{+}{ }_{\mathrm{j}} \quad=\min \{\mathrm{Yij}\} ;$ jika $\mathrm{j}$ adalah atribut biaya $(\cos t$ criteria)

$\mathrm{Y}^{-}{ }_{j}=\max \left\{Y_{i j}\right\} ;$ jika $j$ adalah atribut keuntungan (benefit criteria)

$\mathrm{Y}_{\mathrm{j}}^{-} \quad=\operatorname{maxi}\left\{Y_{\mathrm{j}} \mathrm{j}\right\} ;$ jika $\mathrm{j}$ adalah atribut biaya (cost criteria)

$\mathrm{j} \quad=1,2,3, \ldots, \mathrm{n}$

5. Menghitung separation measure. Separation measure ini merupakan pengukuran jarak dari suatu alternatif ke solusi ideal positif dan solusi ideal negatif. Perhitungan solusi ideal positif dapat dilihat pada persamaan (6):

$$
S_{i}^{+}=\sqrt{\sum_{i=1}^{n}\left(V_{i j}-V_{j}^{+}\right)^{2}}
$$

$$
\text { Dengan } \mathrm{i}=1,2,3, \ldots \ldots \mathrm{m}
$$

Perhitungan solusi ideal negatif dapat dilihat pada persamaan (7):

$$
\begin{aligned}
& S_{i}^{-}=\sqrt{\sum_{i=1}^{n}\left(V_{i j}-V_{j}^{-}\right)^{2}} \\
& \text { Dengan } \mathrm{i}=1,2,3, \ldots \ldots \mathrm{m}
\end{aligned}
$$

6. Menghitung nilai preferensi (V) untuk setiap alternatif. Untuk menentukan ranking tiap-tiap alternatif yang ada maka perlu dihitung terlebih dahulu nilai preferensi dari tiap alternatif. Perhitungan nilai preferensi dapat dilihat melalui persamaan (8).

$$
\begin{gathered}
V_{I}=\frac{\mathrm{s}_{i}^{-}}{\mathrm{s}_{i}^{+}+\mathrm{s}_{i}^{-}} \\
\text {Dimana } 0<V_{i}<1 \text { dan } \mathrm{i}=1,2,3, \ldots \ldots \mathrm{m}
\end{gathered}
$$

Setelah didapat nilai $\mathrm{Vi}+$, maka alternatif dapat diranking berdasarkan urutan Vi. Dari hasil perankingan ini dapat dilihat alternatif terbaik yaitu alternatif yang memiliki jarak terpendek dari solusi ideal dan berjarak terjauh dari solusi ideal negatif.

\section{HASIL DAN PEMBAHASAN}

Pada bagian ini, hasil yang dijelaskan berhubungan dengan tujuan penelitian ini. Tujuan penelitian ini yaitu, menentukan murid paud teladan dengan menggunakan metode Technique for Order Preference by Similarity to Ideal Solution (TOPSIS).

\section{Analisa kriteria-kriteria murid paud teladan}

Berdasarkan hasil analisa didalam menentukan murid paud teladan untuk skala penilaian, terhadap kriteria-kriteria[5]; Kreatif, sopan santun, keluwesan bicara, disiplin dan Jujur. maka dibuat skema didalam penilaian murid paud teladan, sebagai berikut:

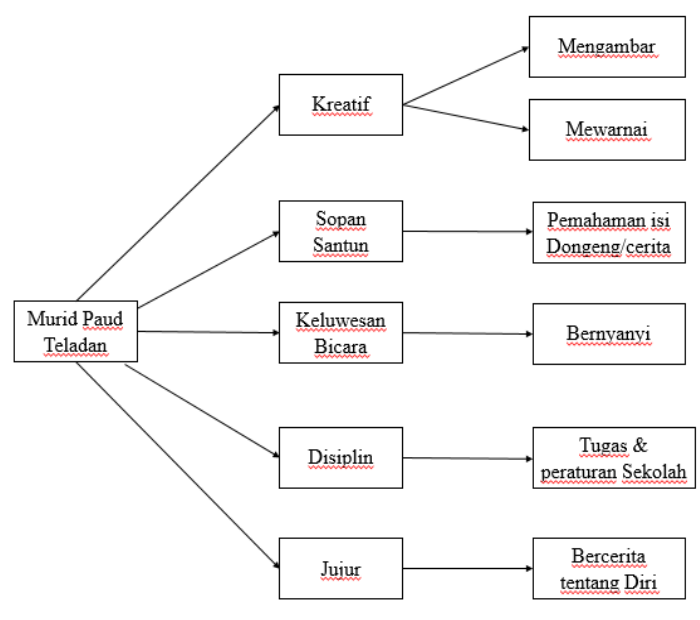

Gambar 2. Skema Penilain Murid Paud Teladan

\section{Pengolahan Data dengan Topsis}

Peneliti melakukan pengolahan data yang diperoleh berdasarkan uraian dari kriteria-kriteria dan bobot dalam menentukan murid paud teladan, maka perlu adanya uraian interval penilaian pada table.1 dan bobot kriteria pada tabel 2. Sebagai berikut ini;

Tabel 1. Interval Penilaian Murid Paud Teladan

\begin{tabular}{ccc}
\hline Interval & Keterangan & Nilai \\
\hline $100-85,00$ & Sangat Baik & 4 \\
$84,99-70,00$ & Baik & 3 \\
$69,99-56,00$ & Cukup & 2 \\
$<=55,99$ & Kurang & 1 \\
\hline
\end{tabular}

Pada Tabel 1. Tujuan berikan penilaian interval sehingga agar lebih mudah untuk mengolah data kedalam metode TOPSIS, dimana ada 4 bagian dalam penilaiannya dalam bentuk keterangan. Yaitu sangat baik, baik, cukup dan kurang. 


\begin{tabular}{ccc}
\hline \multicolumn{3}{l}{ Tabel 2. Bobot Kriteria Penilaian Murid Paud Teladan } \\
\hline Kode Kriteria & Nama Kriteria & Bobot \\
\hline K1 & Kreatif & 5 \\
K2 & Sopan Santun & 3 \\
K3 & Keluwesan Bicara & 2 \\
K4 & Disiplin & 4 \\
K5 & Jujur & 3 \\
\hline
\end{tabular}

Tabel 3. Data Murid Paud

\begin{tabular}{lccccc}
\multicolumn{1}{c}{ Alternatif } & K1 & K2 & K3 & K4 & K5 \\
\hline Alika & 3 & 3 & 2 & 4 & 3 \\
Cindy Clarisa & 4 & 3 & 3 & 3 & 3 \\
M. Hilmansyah & 4 & 3 & 2 & 3 & 4 \\
Mikail & 3 & 4 & 3 & 3 & 3 \\
M. Reyhan & 4 & 3 & 4 & 4 & 3 \\
\hline
\end{tabular}

Data pada tabel 3 merupakan data yang sudah di kuantisasi.

\section{Matriks Keputusan (D)}

Matriks keputusan (D) diambil dari data pada table 3, sebagai berikut:

$$
D=\left[\begin{array}{lllll}
3 & 3 & 2 & 4 & 3 \\
4 & 3 & 3 & 3 & 3 \\
4 & 3 & 2 & 3 & 4 \\
3 & 4 & 3 & 3 & 3 \\
4 & 3 & 4 & 4 & 3
\end{array}\right]
$$

\section{Matriks Normalisasi (R)}

Selanjutnya membuat matriks keputusan normalisasi ${ }^{\circledR}$ yang fungsinya untuk memperkecil range data, agar mudah dalam perhitungan TOPSIS. Setiap normalisasi dari nilai rij dapat dilakukan dengan perhitungan menggunakan persamaan dua.

$$
\begin{aligned}
r_{i j}= & \frac{X_{i j}}{\sqrt{\sum_{n=1}^{m} X_{i j}}} \\
r_{11}= & \left.X 1,1 \sqrt{ } X^{2} 1,1+X^{2} 2,1+X^{2} 3,1+X^{2} 4,1+X^{2} 5,1\right) \\
= & 3 / \sqrt{ }\left(3^{2}+4^{2}+4^{2}+3^{2}+4^{2}\right) \\
& =3 / \sqrt{ }(66)=0.369
\end{aligned}
$$

Tabel 4. Normalisasi Murid Paud Teladan

\begin{tabular}{lccccc}
\hline Alternatif & K1 & K2 & K3 & K4 & K5 \\
\hline Alika & 0.369 & 0.416 & 0.308 & 0.520 & 0.416 \\
Cindy Clarisa & 0.492 & 0.416 & 0.416 & 0.390 & 0.416 \\
M. Hilmansyah & 0.492 & 0.416 & 0.308 & 0.390 & 0.554 \\
Mikail & 0.369 & 0.554 & 0.416 & 0.390 & 0.416 \\
M. Reyhan & 0.492 & 0.416 & 0.617 & 0.390 & 0.416 \\
\hline
\end{tabular}

\section{Bentuk Matriks Normalisasi}

$$
R=\left[\begin{array}{lllll}
0.369 & 0.416 & 0.308 & 0.520 & 0.416 \\
0.492 & 0.416 & 0.416 & 0.390 & 0.416 \\
0.492 & 0.416 & 0.308 & 0.390 & 0.554 \\
0.369 & 0.554 & 0.416 & 0.390 & 0.416 \\
0.492 & 0.416 & 0.617 & 0.390 & 0.416
\end{array}\right]
$$

Pada matrik Normalisasi $\mathrm{R}$ di atas, data perbaris dari baris ke-1 s.d. baris ke- 5 menunjukan data per-alternatif $\mathrm{Ai}$, sedangkan data per-kolom, dari kolom ke-1 s.d. kolom ke-5 adalah data per-kriteria $\mathrm{Cj}$

\section{Matriks Normalisasi Terbobot (Y)}

Langkah berikutnya, dari masing-masing data ternormalisasi (R) kemudian dikalikan dengan bobot (W) untuk mendapatkan matriks keputusan ternormalisasi terbobot Y. Sebagai berikut:

$$
\begin{aligned}
& \mathrm{y}_{1,1}=\mathrm{r}_{1,1}{ }^{*} \mathrm{w}_{1}=0.369 * 5=1.846 \\
& \mathrm{y}_{2,1}=\mathrm{r}_{2,1} * \mathrm{w}_{1}=0.492 * 5=2.461 \\
& \mathrm{y}_{3,1}=\mathrm{r}_{3,1}{ }^{*} \mathrm{w}_{1}=0.492 * 5=2.461 \\
& \mathrm{y}_{4,1}=\mathrm{r}_{4,1}{ }^{*} \mathrm{w}_{1}=0.369 * 5=1.846 \\
& \mathrm{y}_{5,1}=\mathrm{r}_{5,1}{ }^{*} \mathrm{w}_{1}=0.492 * 5=2.461 \\
& \mathrm{y}_{1,2}=\mathrm{r}_{1,2}{ }^{*} \mathrm{w}_{2}=0.416^{*} 3=1.248 \\
& \mathrm{y}_{2,2}=\mathrm{r}_{2,2}{ }^{*} \mathrm{w}_{2}=0.416 * 3=1.248 \\
& \mathrm{y}_{3,2}=\mathrm{r}_{3,2}{ }^{*} \mathrm{w}_{2}=0.416^{*} 3=1.248 \\
& \mathrm{y}_{4,2}=\mathrm{r}_{4,2}{ }^{*} \mathrm{w}_{2}=0.554 * 3=1.664 \\
& \mathrm{y}_{5,2}=\mathrm{r}_{5,2}{ }^{*} \mathrm{w}_{2}=0.416 * 3=1.248 \\
& \mathrm{y}_{1,3}=\mathrm{r}_{1,3}{ }^{*} \mathrm{w}_{3}=0.308 * 2=0.617 \\
& y_{2,3}=r_{2,3} * w_{3}=0.416 * 2=0.832 \\
& \mathrm{y}_{3,3}=\mathrm{r}_{3,3}{ }^{*} \mathrm{~W}_{3}=0.308 * 2=0.617 \\
& \mathrm{y}_{4,3}=\mathrm{r}_{4,3}{ }^{*} \mathrm{~W}_{3}=0.416 * 2=0.832 \\
& \mathrm{y}_{5,3}=\mathrm{r}_{5,3}{ }^{*} \mathrm{w}_{3}=0.617^{*} 2=0.617 \\
& \mathrm{y}_{1,4}=\mathrm{r}_{1,4}{ }^{*} \mathrm{~W}_{4}=0.520 * 4=2.083 \\
& \mathrm{y}_{2,4}=\mathrm{r}_{2,4}{ }^{*} \mathrm{~W}_{4}=0.390 * 4=1.562 \\
& \mathrm{y}_{3,4}=\mathrm{r}_{3,4} * \mathrm{~W}_{4}=0.390 * 4=1.562 \\
& \mathrm{y}_{4,4}=\mathrm{r}_{4,4}{ }^{*} \mathrm{w}_{4}=0.390 * 4=1.562 \\
& \mathrm{y}_{5,4}=\mathrm{r}_{5,4}{ }^{*} \mathrm{~W}_{4}=0.390 * 4=1.562 \\
& \mathrm{y}_{1,5}=\mathrm{r}_{1,5}{ }^{*} \mathrm{~W}_{5}=0.416 * 3=1.248 \\
& \mathrm{y}_{2,5}=\mathrm{r}_{2,5} * \mathrm{w}_{5}=0.416 * 3=1.248 \\
& \mathrm{y}_{3,5}=\mathrm{r}_{3,5} * \mathrm{~W}_{5}=0.554 * 3=1.664 \\
& \mathrm{y}_{4,5}=\mathrm{r}_{4,5}{ }^{*} \mathrm{~W}_{5}=0.416 * 3=1.248 \\
& \mathrm{y}_{5,5}=\mathrm{r}_{5,5}{ }^{*} \mathrm{~W}_{5}=0.416^{*} 3=1.248
\end{aligned}
$$

Dari semua data pada matrik normalisasi $\mathrm{R}$ dilakukan perhitungan yang sama dengan perhitungan tersebut, sehingga diperoleh matriks Normalisasi Terbobot (Y) sebagai berikut: 


$\mathrm{Y}=\left[\begin{array}{lllll}1.846 & 1.248 & 0.617 & 2.083 & 1.248 \\ 2.461 & 1.248 & 0.832 & 1.562 & 1.248 \\ 2.461 & 1.248 & 0.617 & 1.562 & 1.664 \\ 1.846 & 1.664 & 0.832 & 1.562 & 1.248 \\ 2.461 & 1.248 & 0.617 & 1.562 & 1.248\end{array}\right]$

Tabel 4. Normalisasi Berbobot

\begin{tabular}{lccccc}
\hline \multicolumn{1}{c}{ Alternatif } & K1 & K2 & K3 & K4 & K5 \\
\hline \multicolumn{1}{c}{ Bobot } & 5 & 3 & 2 & 4 & 3 \\
\hline Alika & 1.846 & 1.248 & 0.617 & 2.083 & 1.248 \\
Cindy Clarisa & 2.461 & 1.248 & 0.925 & 1.562 & 1.248 \\
M. Hilmansyah & 2.461 & 1.248 & 0.617 & 1.562 & 1.664 \\
Mikail & 1.846 & 1.664 & 0.925 & 1.562 & 1.248 \\
M. Reyhan & 2.461 & 1.248 & 1.234 & 2.083 & 1.248 \\
Max & 2.461 & 1.664 & 1.234 & 2.083 & 1.664 \\
Min & 1.846 & 1.248 & 0.617 & 1.562 & 1.248 \\
\hline
\end{tabular}

Matriks Solusi Ideal Positif $\left(\mathrm{A}^{+}\right)$dan Negatif $\left(\mathrm{A}^{-}\right)$

Matriks Solusi Ideal (A) merupakan nilai optimum untuk tiap-tiap kriteria, dari beberapa nilai alternatif solusi. Solusi ideal yang dicari terdiri dari dua nilai untuk masing-masing kriteria, yaitu Solusi Ideal Positif $\left(\mathrm{A}^{+}\right)$dan Solusi Ideal Negatif $\left(\mathrm{A}^{-}\right)$

Tabel 5. Solusi ideal murid paud teladan

\begin{tabular}{lrrrrr}
\hline Alternatif & K1 & K2 & K3 & K4 & K5 \\
\hline Positive & 2.461 & 1.664 & 1.234 & 2.083 & 1.664 \\
Negative & 1.846 & 1.248 & 0.617 & 1.562 & 1.248 \\
\hline
\end{tabular}

Menentukan nilai solusi ideal positif dan solusi ideal negatif. Solusi ideal dinotasikan $\mathrm{A}^{+}$, sedangkan solusi ideal negatif dinotasikan $\mathrm{A}^{-}$.

\section{Solusi Ideal Positif $\left(\mathrm{A}^{+}\right)$}

Solusi Ideal Positif $\left(\mathrm{A}^{+}\right)$merupakan nilai optimum maksimum (terbesar) dari suatu kriteria untuk beberapa nilai alternatif solusi dalam satu kriteria.

Tabel 6. Jarak Solusi Positive

\begin{tabular}{lcccccc}
\multicolumn{1}{c}{ Alternatif } & K1 & K2 & K3 & K4 & K5 & TOTAL \\
\hline Alika & 0.378 & 0.173 & 0.380 & 0 & 0.173 & 1.105 \\
Cindy Clarisa & 0 & 0.173 & 0.095 & 0.271 & 0.173 & 0.712 \\
M. Hilmansyah & 0 & 0.173 & 0.380 & 0.271 & 0 & 0.825 \\
Mikail & 0.378 & 0 & 0.095 & 0.271 & 0.173 & 0.918 \\
M. Reyhan & 0 & 0.173 & 0 & 0 & 0.173 & 0.346 \\
\hline
\end{tabular}

\section{Solusi Ideal Negatif ( $\left.\mathrm{A}^{-}\right)$}

Solusi Ideal Negatif $\left(A^{-}\right)$merupakan nilai optimum minimum (terkecil) dari suatu kriteria untuk beberapa nilai alternatif solusi dalam satu kriteria.
Tabel 7. Jarak Solusi Negative

\begin{tabular}{lcccccc}
\hline \multicolumn{1}{c}{ Alternatif } & K1 & K2 & K3 & K4 & K5 & TOTAL \\
\hline Alika & 0 & 0 & 0 & 0.271 & 0 & 0.271 \\
Cindy Clarisa & 0.378 & 0 & 0.095 & 0 & 0 & 0.474 \\
M. Hilmansyah & 0.378 & 0 & 0 & 0 & 0.173 & 0.551 \\
Mikail & 0 & 0.173 & 0.095 & 0 & 0 & 0.268 \\
M. Reyhan & 0.378 & 0 & 0.380 & 0.271 & 0 & 1.031 \\
\hline
\end{tabular}

\section{Nilai Preferensi (V)}

Menghitung nilai preferensi untuk setiap alternative. Untuk menentukan ranking tiap-tiap alternative yang ada maka perlu dihitung terlebih dahulu nilai preferensi dari alternative. Perhitungan nilai preferensi.

Setelah didapatkan nilai Vi, maka alternative dapat diranking berdasarkan urutan Vi. Dari hasil perankingan ini dapat dilihat alternative terbaik yaitu alternative yang dimiliki jarak dari solusi ideal

Tabel 8. Nilai Preferensi

\begin{tabular}{lcccc}
\hline Alternatif & Positif & Negatif & Preferensi & Ranking \\
\hline Alika & 1.106 & 0.271 & 0.516 & 5 \\
Cindy & 0.712 & 0.474 & 1.139 & 3 \\
Clarisa & & & & \\
M. & 0.825 & 0.551 & 1.220 & 2 \\
Hilmansyah & & & & \\
Mikail & 0.918 & 0.268 & 0.561 & 4 \\
M. Reyhan & 0.346 & 1.031 & 4.009 & 1 \\
\hline
\end{tabular}

\section{Hasil Perhitungan dengan Metode TOPSIS}

Hasil dari perhitungan dengan metode topsis menentukan murid Paud Telada kriteria didapat hasilnya yaitu : M. Reyhan (4.009), M. Hilmansyah (1.220), Cindy Clarisa (1.139), Mikail (0.560) dan Alika (0.516). Sehingga preferensi tertinggi dalam menentukan murid pau teladan adalah M. Reyhan dan terendah adalah Alika. Berdasarkan pada table 8. Nilai Preferensi.

\section{KESIMPULAN}

Simpulan berfungsi untuk mengingatkan pembaca akan argumen penting yang dibangkitkan dalam pembahasan, fokus pada tujuan atau pertanyaan penelitian. Tarik semua perincian menjadi pernyataan umum dari semua argumen. Berdasarkan hasil penelitian yang telah dilakukan dengan menggunakan metode TOPSIS, sehingga diperoleh dalam penilaian MURID PAUD TELADAN adalah M. Reyhan . 
Dari hasil penelitian, dapat disimpulkan halhal sebagai berikut:

1. Metode Topsis dapat dijadikan sebagai alat bantu dalam menentukan murid paud teladan

2. Hasil dari perhitungan dengan metode topsis menentukan murid Paud Telada kriteria didapat hasilnya yaitu: M. Reyhan (4.009159391), M. Hilmansyah (1.22061695), Cindy Clarisa (1.139252405), Mikail (0.56050508) dan Alika (0.516405616). Sehingga preferensi tertinggi dalam menentukan murid pau teladan adalah $\mathrm{M}$. Reyhan dan terendah adalah Alika.

\section{SARAN}

Pada penelitian selanjutnya disarankan peneliti dapat menggunakan metode TOPSIS dengan materi yang beda, sehingga hasilnya dapat lebih detail.

\section{DAFTAR PUSTAKA}

[1] Efraim Turban, et al. (2005). Decision Support System and Intelegence System Ed. 7, PrenticeHall.

[2] Suryandini Afrian, dan Indriyati. 2015. "Sistem Pendukung Keputusan untuk Penentuan Minat Peserta Didik di SMA Menggunakan Metode TOPSIS". Jurnal Masyarakat Informatika. 6, 11.

[3] Turminanto, INFOKES, VOL. 2 NO. 1 Agustus 2012 ISSN: 2086 - 2628, "Sistem Pendukung Keputusan Dengan Metode Analytical Hierarchy Process (AHP) Untuk Presentasi Kinerja Dokter Pada RSUD Sukoharjo", APIKES Citra Medika Surakarta, Surakarta.

[4] W.R, Borg dan M.D, Gall, 1989; "Educational Research An Introduction Fifth Edition", New York: Longman.

[5] Fristy Riandari dkk. 2017. "Sistem Pendukung Keputusan Menggunakan Metode Topsis Dalam Memilih Kepala Departemen Pada Kantor Balai Wilayah Sungai Sumatera II Medan". Journal of Informatic Pelita Nusantara. Volume 2 No 1 Oktober 2017 e-ISSN 2541-3724.

[6] Irvan Muzakkir. 2017. "Penerapan Metode Topsis Untuk Sistem Pendukung Keputusan Penentuan Keluarga Miskin Pada Desa Panca Karsa II" ILKOM Jurnal Ilmiah Volume 9 Nomor 3 Desember 2017. ISSN print 2087-1716 ISSN online 2548-7779.

[7] Mutiah, Diana. Psikologi Bermian Anak Usia Dini. Jakarta: Prenada Media Group. 2010.
[8] Amri, Sofan. Pengembangan dan Model Pembelajaran dalam Kurikulum,.Jakarta: Prestasi Pustakarya. 2016.

[9] Luthfi Nur Hidayat. 2016.Metode Topsis Untuk Membantu Pemilihan Jurusan Pada Sekolah Menengah Atas. Program Studi Informatika/Ilmu Komputer Universitas Dian Nuswantoro Semarang. 